\title{
Enhancing Collaborative Problem-Solving Competencies by Using STEM-Based Learning Through the Dietary Plan Lessons
}

\author{
Tassaneewon Lertcharoenrit ${ }^{1}$ \\ ${ }^{1}$ Kasetsart University Laboratory School, Faculty of Education, Kasetsart University, Bangkok, Thailand \\ Correspondence: Tassaneewon Lertcharoenrit, Kasetsart University Laboratory School, Faculty of Education, \\ Kasetsart University, Bangkok, Thailand. E-mail: Tassaneewon.1@ku.th
}

Received: May 20, 2020

doi:10.5539/jel.v9n4p102
Accepted: June 26, 2020 Online Published: July 1, 2020

URL: https://doi.org/10.5539/jel.v9n4p102

\begin{abstract}
This classroom action research aims to investigate the development of collaborative problem-solving competencies using STEM-based learning through dietary plan lessons. The participants included 77 twelfth-grade students in the 2018 academic year in the science-technology program in a public school under the supervision of the Ministry of University Affairs. Two types of instruments were used in the study: 1) ten lesson plans of the biomolecules unit equivalent to eighteen lesson periods; 2) data collection instruments, including collaborative problem-solving competencies observation sheets, students' learning reflections, and informal interview protocols. The data analysis involved frequencies, percentages, and content analysis. The results of the study revealed that the students improved all three competencies. Regarding the first competency, "Establishing and Maintaining Shared Understanding," the students were accustomed to having a dominant member assigning the task while other members passively followed the orders. When they encountered a problem, each member individually solved it or asked the teachers for help without a group discussion. However, after the instruction, the students improved their communication skills by discussing the task processes with the other group members. Moreover, when a problem occurred, they approached it as a shared responsibility instead of as an individual's duty. Therefore, the problem was collectively sorted out and successfully solved. In terms of the second competency, "Taking Appropriate Action to Solve the Problem," the students had previously been assigned their roles by the group leaders without consideration of the strengths and weaknesses of each member, resulting in an unsuccessful task. After the instruction, everyone became more collaborative in considering the task at hand and discussed the role that best suited each member. When they encountered a problem, everyone collectively planned the appropriate steps toward the solution. With regard to the third competency, "Establishing and Maintaining Team Organization," the students had not previously reflected on their performance, but after the activities, they learned to provide feedback to improve other members' understanding and carry out the task more efficiently. A challenge that emerged in implementing the activities involved the time issue. It is important to manage time effectively and to challenge the students to collaboratively solve the problem. The instructional activities should be conducted continuously by rotating students into new groups where they can practice their teamwork skills with others. Moreover, the collaborative problem-solving activities are found to be applicable not only for a STEM-based approach but also for a project-based approach.
\end{abstract}

Keywords: collaborative problem-solving competencies, STEM-based learning

\section{Introduction}

The world we live in is without borders and characterized by constant changes and numerous problems. We need to realize that we cannot live and face all these obstacles alone. Creative teamwork and problem-solving are essential life skills (Hesse et al., 2015; Nelson, 1999). This is consistent with the position of the Basic Education Commission (2012), which asserts that problem-solving and collaborative skills are the crucial components of life skills in the 21st century (Griffin \& Care, 2014; Binkley et al., 2012). These skills will enable young generations to cope with the current changes as well as the problems they will encounter in the future. According to the Organization for Economic Co-operation and Development's (OECD) (2017), collaborative problem-solving is an essential competency essential for learning and working, as it promotes learners' ability to find effective solutions to problems through collective work with other group members. Facing a problem and trying to solve it alone may not be as effective as doing it as a team. Coordination results in more alternatives 
and myriad approaches to the problem (Barron, 2000; Hennessy \& Murphy, 1999; Innes, 2007). Collaborative problem-solving (CPS) competency refers to the capacity of a learner to collaborate with other members of a group to solve problems in different situations. The CPS competency consists of three sub-competencies: 1) establishing and maintaining shared understanding; 2) taking appropriate action to solve the problem; and 3) establishing and maintaining team organization (Nelson, 1999).

Studies related to CPS competencies have mainly examined the outcomes of using the CPS framework on students' learning (Bungum, Bøe, \& Henriksen, 2018; Rozenszayn \& Ben-Zvi Assaraf, 2011; Tao, 1999) without considering how the group work process affected the students' learning outcomes. These studies only highlighted the improved performance of the students after the group work process. A few studies even found that group work did not produce better outcomes than individual work (Sampson \& Clark, 2009). This negative result could be due to the students' lack of practice in CPS when the teacher assigned them a group task. Often, the task was ultimately completed by a single person, especially the group leader (Innes, 2007).

However, as an increasing number of studies reported the success of the collaborative inquiry approach, more researchers started to pay attention to the factors that contribute to successful collaboration. Besides the emphasis on the content itself, many studies began to focus on the emotion and stress that occurred during the group process, including methods learners used to cope with tension and conflict due to group arguments (Lamminpää \& Vesterinen, 2018; Sohr, Gupta, \& Elby, 2018).

The researcher, as a teacher, is fully aware of the important task of preparing learners for all necessary skills, especially when the students exhibit no CPS behaviors. Based on the researcher's observation, only one or two students in a group of four or five normally bear the responsibility of completing the task. There was a low level of engagement and interaction among the group members. The group leader gave orders and was in charge of dividing the tasks for each member. Moreover, the group members did not plan the whole task together. When there was a problem during the task process, the group leader solved the problem without asking the other members for their opinions. If the issue arose during the final work presentation, it was the sole responsibility of the leader. This might also be the case in other classrooms in Thailand. According to the Programme for International Student Assessment (PISA, 2003), a majority of Thai students have a low level of CPS competencies. Therefore, the lack of CPS competencies among Thai students requires as much attention as the development of cognitive competence at the national level, both of which educators should prioritize.

Based on the aforementioned problem, the researcher attempted to develop instruction that enhances CPS competencies by emphasizing the development of skills contributing to group work achievement. The review of the previous research revealed that most studies only focused on using various techniques, approaches, and concepts that helped with the problem-solving and group work processes. However, CPS competencies, which are an essential skill, require interdisciplinary knowledge and a combination of skills to effectively enhance learners' CPS competencies (Kim \& Tan, 2013).

Therefore, the researcher believed that CPS competencies combined with STEM-based education would likely lead to better learning outcomes. According to Suthida Jamrus (2017), the six main features of STEM-based education include (1) the integrated approach of teaching science, technology, engineering, and mathematics, focusing on STEM understanding and knowledge; (2) the learning innovation framework; (3) context-based learning; (4) 21st-century learning; (5) design and problem-solving activities; and (6) authentic assessment and evaluation. Based on the study of Edmunds et al. (2017), the combination of STEM-based and project-based approaches leads to the development of CPS skills. This finding is consistent with those of Bybee (2013) and Radloff and Guzey (2016), who concluded that STEM-based learning can facilitate students' application of integrated knowledge to design innovation to solve a problem based on their creativity and collaborative skills. Therefore, to prepare learners for the 21 st century, the researcher aimed to use dietary program planning lessons based on the STEM education framework to enhance the students' CPS competencies.

\subsection{Objectives of the Study}

The objective was to study the results of CPS competency development based on STEM-based learning through dietary plan lessons.

\section{Research Methodology}

This study was based on classroom action research, the purpose of which is to find the best way to develop students' learning. The researcher, as a teacher, collected the qualitative data using the Kemmis' action research process (Kemmis \& McTaggart, 1988), which consists of three phases in a cycle of planning, acting and observing, and reflecting. The three phases are continuously repeated in four cycles, as shown in Figure 1. 


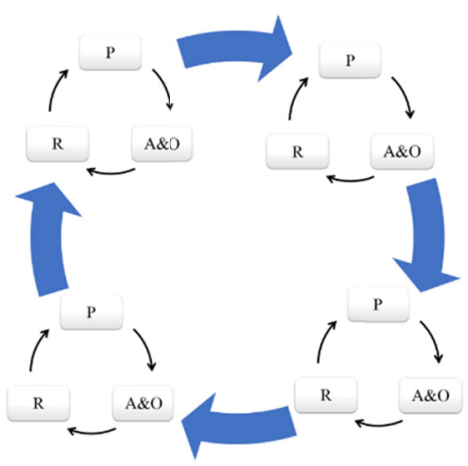

Figure 1. The process cycle of classroom action research used in the study

\subsection{The Participants}

The participants were 12th-grade students in the science and technology track from three classrooms in which the researcher taught during the second semester in 2018. In total, there were 77 participants (40 male students and 37 female students).

\subsection{The Innovative Lesson Plan}

The researcher designed ten-unit lesson plans, which include 18 hours of lessons on biomolecules. The lessons were divided into five stages as follows: Stage 1: Identifying the problem; Stage 2: Exploring and gathering information; Stage 3: Planning the diet program; Stage 4: Evaluating and revising the plan; and Stage 5: Concluding and presenting the results. Upon completing the lesson design, the researcher asked a group of experts, consisting of scientists, science educators, and experienced teachers, to validate the lessons. The lessons were then revised according to the experts' feedback before the actual lesson implementation. The STEM-based lesson plans on biomolecules are presented in Table 1. 
Table 1. Detailed lesson plans on the STEM-based biomolecules

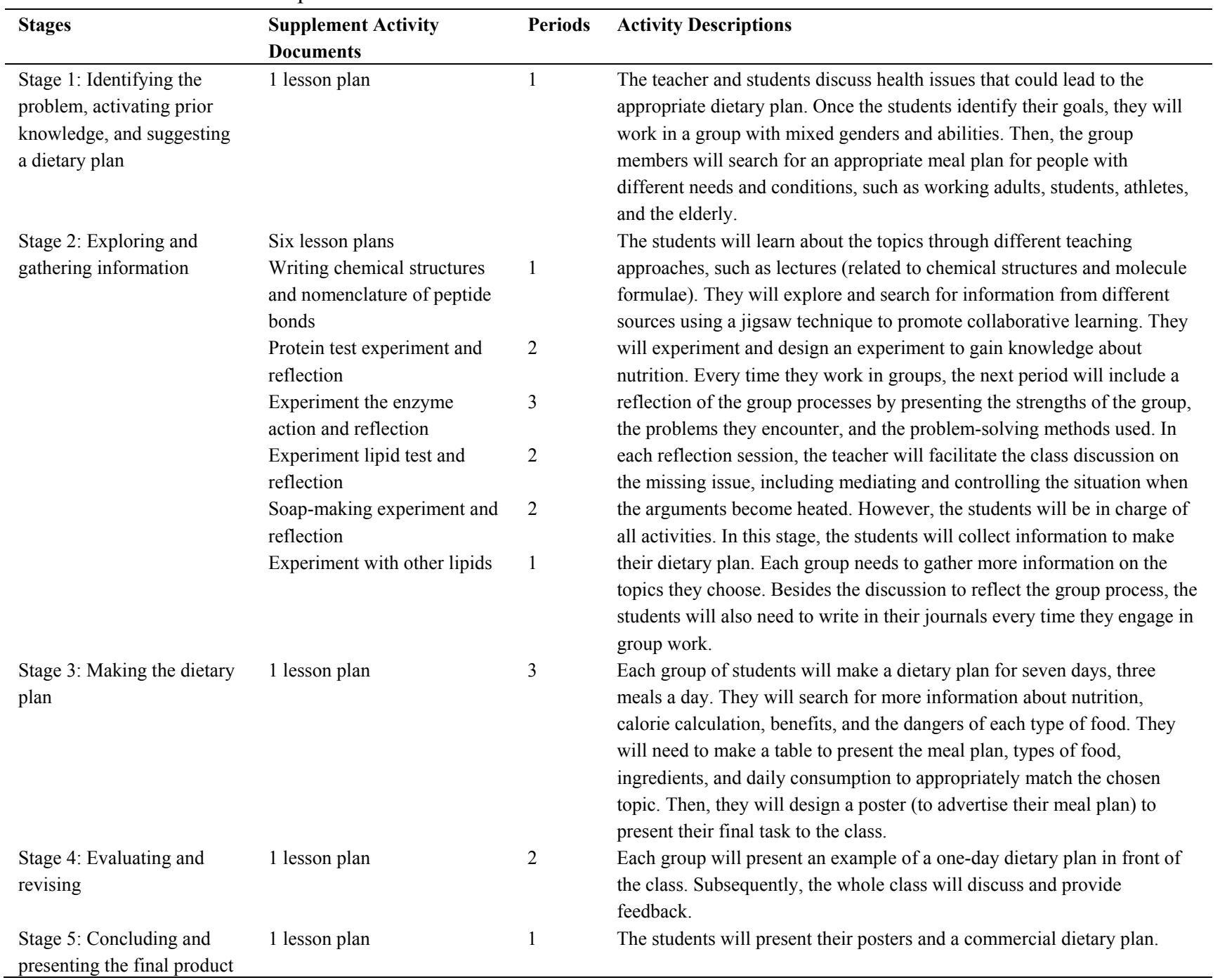

\subsection{Research Instrument}

The following research instruments were used for data collection:

(1) The Collaborative Problem-Solving (CPS) Observation Form. This form consists of seven rating scale questions regarding the group members' behaviors. The observation protocol was adapted from the study of Lertdechapat and Promrat (2015). This observation protocol was utilized to evaluate collaborative behavior, which is a crucial skill for the 21st century. The sample sheet of the CPS Observation Form is shown below. 


\begin{tabular}{|c|c|c|c|c|c|c|c|c|}
\hline \multirow[t]{2}{*}{ Member's Behaviors } & \multicolumn{4}{|c|}{ The First Observation } & \multicolumn{4}{|c|}{ The Second Observation } \\
\hline & 3 & 2 & 1 & $\begin{array}{l}\text { Example of the incident, } \\
\text { details of the talk, } \\
\text { conversation }\end{array}$ & 3 & 2 & 1 & $\begin{array}{l}\text { Example of the incident, } \\
\text { details of the talk, } \\
\text { conversation }\end{array}$ \\
\hline $\begin{array}{l}\text { 1. Before the task, the } \\
\text { members work } \\
\text { collectively to discuss the } \\
\text { steps to be taken. }\end{array}$ & & & & & & & & \\
\hline $\begin{array}{l}\text { 2. When the problem occurs, } \\
\text { the members discuss how } \\
\text { to solve the problem } \\
\text { without getting off track. }\end{array}$ & & & & & & & & \\
\hline $\begin{array}{l}\text { 3. Members build agreement } \\
\text { and divide the tasks } \\
\text { equally based on each } \\
\text { member's potential. }\end{array}$ & & & & & & & & \\
\hline $\begin{array}{l}\text { 4. Menbers follow and } \\
\text { execute the plan based on } \\
\text { the assigned role. }\end{array}$ & & & & & & & & \\
\hline $\begin{array}{l}\text { 5. Members discuss the } \\
\text { progress of the task and } \\
\text { how to solve the problems } \\
\text { that occurred during their } \\
\text { task }\end{array}$ & & & & & & & & \\
\hline $\begin{array}{l}\text { Members reflect and } \\
\text { provide feedback on their } \\
\text { tasks, responsibilities, and } \\
\text { the working process. }\end{array}$ & & & & & & & & \\
\hline
\end{tabular}

Figure 2. The collaborative problem-solving (CPS) observation form

(2) Students' Reflection Form. This is a tool to help students record what they learned. The researcher instructed the students to write a reflection at the end of each period including obstacles and suggestions for all ten classes. The students were assigned questions to write about in their reflections, such as: What did you learn from doing this activity (in terms of both content and task)? Did you have any problems while performing your task, and how did you solve them?

(3) Informal Interview Protocol. The researcher used the informal interview protocol to record the students' interviews to deeply investigate topics that were important or unclear. This kind of interview is flexible. The question can be adjusted or rephrased until the students understand, so the information is shared between the researcher and the participants. If there is any misunderstanding, it can be corrected immediately. When the researcher read the participants' reflections and found any incomplete, ambiguous answers that needed further elaboration, the researcher could follow up with an informal interview on a case-by-case basis.

\subsection{Data Collection}

The researcher asked the students to complete the CPS observation form after the first group work session. Subsequently, the researcher organized instructional activities that followed four cycles of the three spiral stages of classroom action research: plan, act and observe, and reflect. The information from the first cycle was used to analyze the development of the CPS competencies and then to improve the group dynamics based upon the members' reflection before moving on to the next four cycles. During the instruction, the researcher acted as an observer and facilitated the group working process. At the end of each lesson, the researcher instructed the students to complete the reflection form to record the knowledge and learning activities. In the final lesson, the researcher asked each student to complete the CPS competencies observation form again. Moreover, the researcher interviewed the students for additional comments, details of the talk/conversations, or unclear incidents.

\subsection{Data Analysis}

The researcher analyzed the information from the data gathered by calculating frequencies, percentages, and conducting a content analysis. To check the reliability, the data were triangulated by cross-analyzing the students' responses from the CPS observation, the students' reflection, and the informal interview (Cohen et al., 2007). Subsequently, the researcher categorized the data into three groups: 1) the opinions or behaviors of the students that always or regularly demonstrate the competencies; 2) the opinions or behaviors of the students that often or sometimes demonstrate the competencies; and 3) the opinions or behaviors of the students that occasionally demonstrate the competencies. After the data analysis, the researcher asked the participants to review the data to check the accuracy of the data interpretation. Table 2 below shows how the data were sorted and analyzed. 
Table 2. The data coding scheme

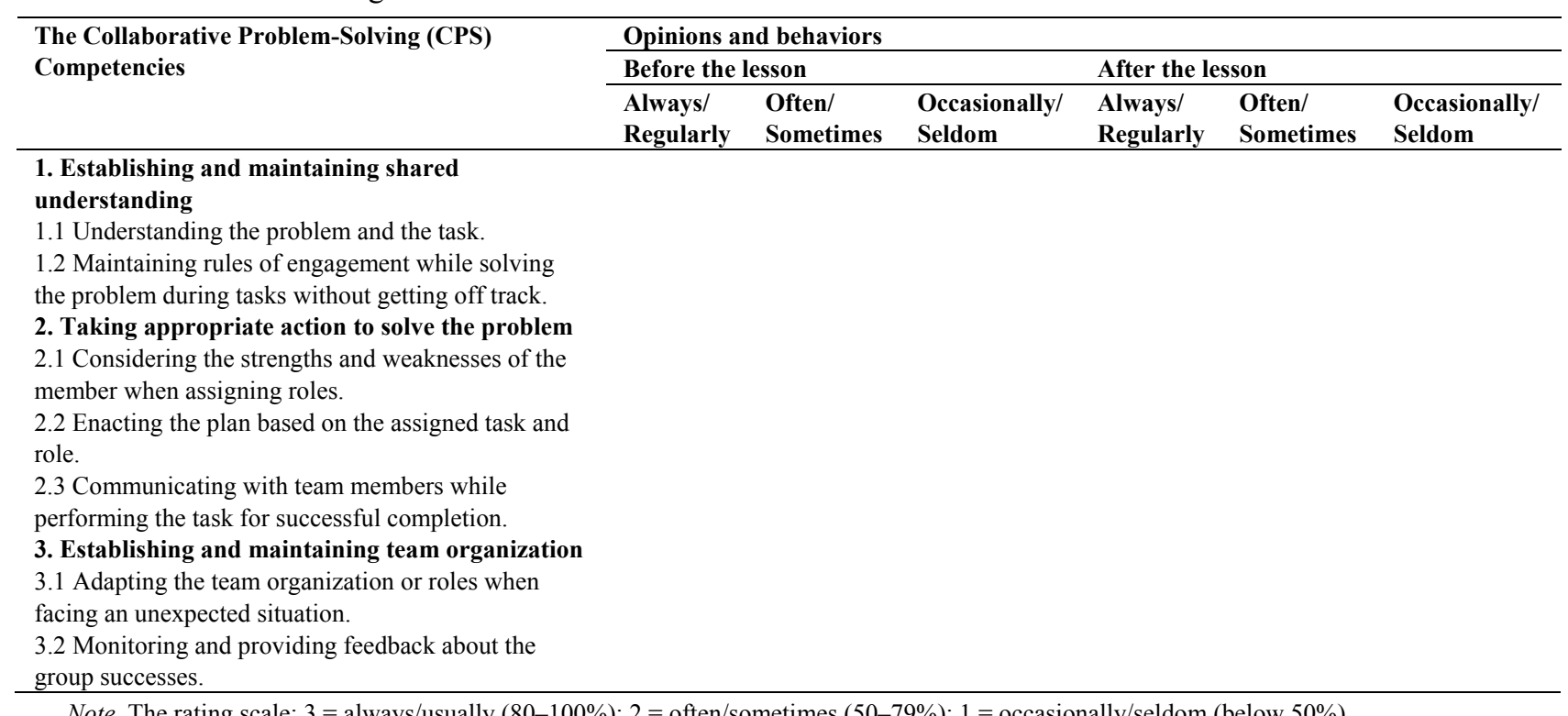

Note. The rating scale: $3=$ always/usually $(80-100 \%) ; 2=$ often/sometimes (50-79\%); $1=$ occasionally/seldom (below $50 \%$ ).

\section{Findings}

The researcher found that STEM-based learning through dietary plan lessons enhanced the CPS competencies. When considering the average scores across seven competencies before and after the lessons, the students gained the highest average score $(X=2.4)$ in Competency 2.2 , which was about enacting the plan based on the assigned task and role. Competency 2.3 , which was concerned with communicating with team members while performing the task for successful completion, received the lowest average score $(\mathrm{X}=2.02)$. After the activities, the average scores of each competency increased, as shown in Figure 3.

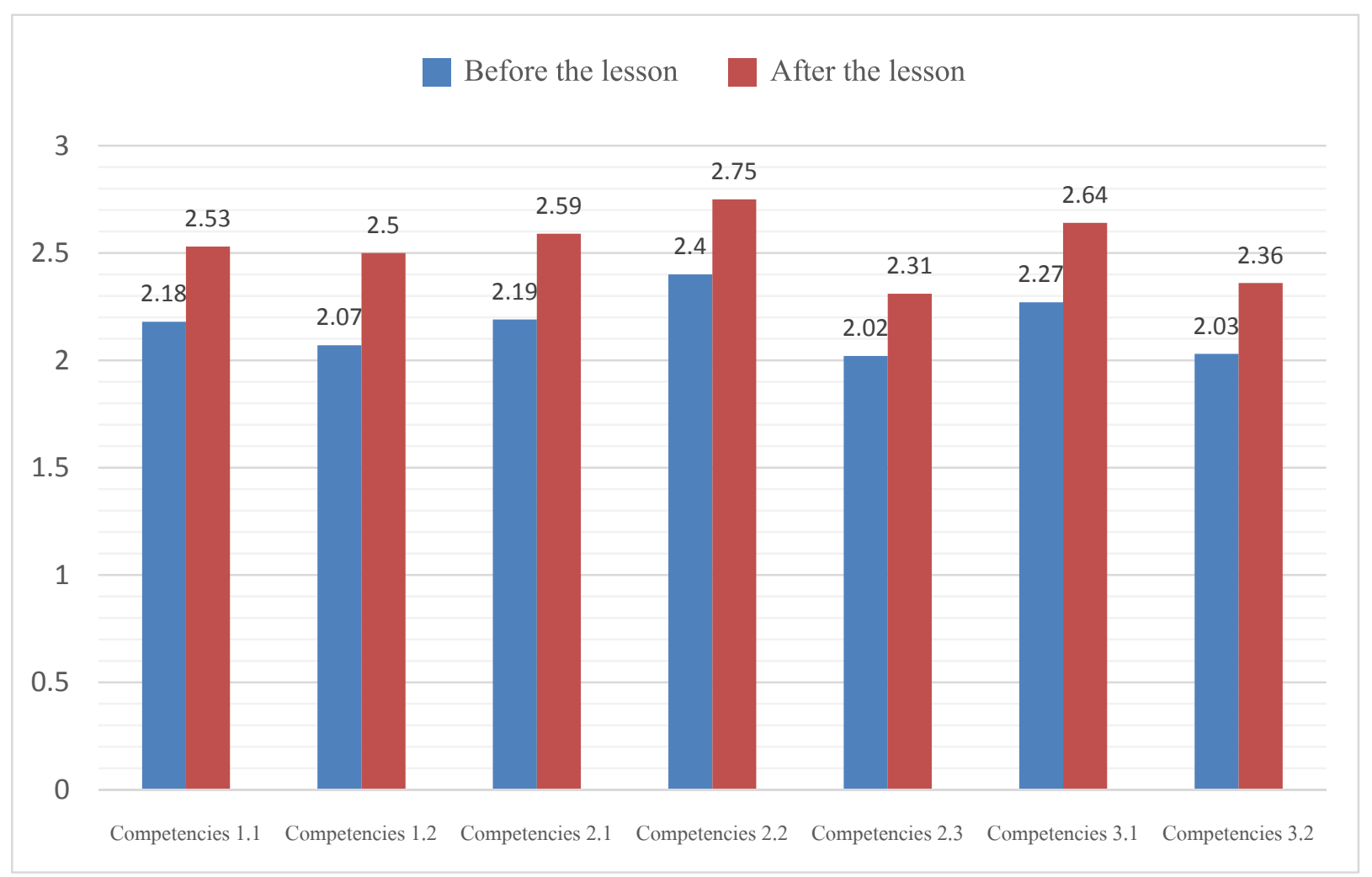

Figure 3. The average scores of the CPS competencies 
In teaching the chemistry class, the researcher typically assigned the students to perform group experiments. Based on the researcher's observation, the students often behaved similarly. At the beginning of an experiment, they often walked aimlessly following one another to where the equipment was placed. Some group leaders knew what they needed and picked up their equipment for their groups, while other members who were gathered around the equipment table came back to their groups. Then, the group leaders started the experiment by ordering other members to pick up more materials, keep track of time, or take notes on the experiment. When the researcher walked around to ask them what they were doing, many students could not explain their experiment. Some said they took notes when their peers told them to. The students who did not engage in the lessons waited for the equipment clean-up time. If they had any questions, they might ask the teacher. If there was more than one step for any experiment, even the group leader needed to ask the teacher what to do next, even though the steps had been explained immediately before the beginning of the experiment. These were the observable behaviors before the introduction of STEM-based learning. When the students filled out the first CPS form before the lesson started, it was found that, for Competency 2.2: Enacting the plan based on the assigned task and role, the students had an average score of 2.4. Some of the behaviors that the students believed involved enacting the plan based on the assigned task were stated as follows:

"Everybody in our group carried out the assigned task." S9

"Once assigned, our group members fully performed their task." S22

"Everybody was assigned what to do and did their best." S26

Competency 2.3 concerning communicating with team members while performing the task for successful completion was rarely seen in group dynamics, with a mean score of 2.02 . The students who believed this competency was rarely observed in their group works expressed the following opinions:

"Mostly when the students were assigned their roles, they would do their parts without looking at the big picture." S7

"When they completed their duties, they did not care to help other members who had not finished the task." S15

"Everybody was busy working on their tasks, they did not communicate with each other while working." S49

Next, the researcher implemented the 10-unit, 18-period lessons on biomolecules that were designed using the STEM-based learning. After completing each group activity, the students needed to write their reflection. They would then use this reflection to improve their group processes. At the end of the implementation, the researcher asked each student to complete the CPS observation form for a second time. The results revealed certain competencies that the students had developed by performing the following actions more frequently. For instance, regarding Competency 1.2, when a problem occurred, members of the group negotiated to find a way to solve it. The average score of this competency jumped from 2.07 to 2.50 after the implementation. Similarly, scores for Competency 1.1, discussing and understanding before starting the task, increased from 2.18 to 2.58 . The scores for Competency 2.1, assigning roles based on the members' potentials, also increased from 2.19 to 2.59.

The development of CPS competencies can be examined based on the three key competencies: 1) establishing and maintaining a shared understanding; 2) taking appropriate action to solve the problem; and 3) establishing and maintaining team organization. Each core competency was categorized in one of three levels: 1) the member rarely or never displays the behavior; 2) the member displays the behavior but not regularly; and 3) the member often and regularly displays the behavior. The findings regarding the behaviors before and after the instruction are shown in Table 3. 
Table 3. Collaborative problem-solving (CPS) competencies scores

\begin{tabular}{|c|c|c|c|c|c|c|}
\hline \multirow[t]{3}{*}{ Collaborative Problem-Solving (CPS) Competencies } & \multicolumn{6}{|c|}{ Scores of the Competencies (Percentage $(\mathrm{N})$ ) } \\
\hline & \multicolumn{3}{|c|}{ First Assessment } & \multicolumn{3}{|c|}{ Second Assessment } \\
\hline & 3 & 2 & 1 & 3 & 2 & 1 \\
\hline \multicolumn{7}{|l|}{$\begin{array}{l}\text { 1. Establishing and maintaining a shared } \\
\text { understanding }\end{array}$} \\
\hline 1.1 Understanding the problem and the task. & $31.17(24)$ & $55.84(43)$ & $12.99(10)$ & $62.33(48)$ & $33.77(26)$ & $3.90(3)$ \\
\hline $\begin{array}{l}\text { 1.2 Maintaining rules of engagement while solving the } \\
\text { problem during tasks without getting off track. }\end{array}$ & $25.98(20)$ & $55.84(43)$ & $18.18(14)$ & $57.14(44)$ & $36.35(28)$ & $6.49(5)$ \\
\hline \multicolumn{7}{|l|}{ 2. Taking appropriate action to solve the problem } \\
\hline $\begin{array}{l}\text { 2.1 Considering the strengths and weaknesses of the } \\
\text { member when assigning roles. }\end{array}$ & $33.76(26)$ & $53.25(41)$ & $12.99(9)$ & $64.94(50)$ & $29.87(23)$ & $5.19(4)$ \\
\hline 2.2 Enacting the plan based on the assigned task and role. & $48.05(37)$ & $44.16(34)$ & $7.79(6)$ & $77.92(60)$ & $19.48(15)$ & $2.60(2)$ \\
\hline $\begin{array}{l}2.3 \text { Communicating with team members while performing } \\
\text { the task for successful completion. }\end{array}$ & $31.17(24)$ & $40.26(31)$ & $28.57(22)$ & $42.86(33)$ & $45.45(35)$ & $11.69(9)$ \\
\hline \multicolumn{7}{|l|}{$\begin{array}{l}\text { 3. Adapting the team organization or roles when } \\
\text { facing an unexpected situation. }\end{array}$} \\
\hline $\begin{array}{l}3.1 \text { Monitoring and providing feedback about the group } \\
\text { success. }\end{array}$ & $41.55(32)$ & $44.16(34)$ & $14.29(11)$ & $70.13(54)$ & $24.68(19)$ & $5.19(4)$ \\
\hline $\begin{array}{l}3.2 \text { Adapting the team organization or roles when facing } \\
\text { an unexpected situation. }\end{array}$ & $29.87(23)$ & $44.16(34)$ & $25.97(20)$ & $45.45(35)$ & $45.45(35)$ & $9.10(7)$ \\
\hline
\end{tabular}

The first competency, establishing and maintaining shared understanding, consists of two components: competency 1.1: Understanding the problem and the task; and competency 1.2: Maintaining rules of engagement while solving the problem during tasks without getting off track. The detailed results of the competencies are presented next.

\section{Competency 1.1 Understanding the Problem and the Task}

In understanding the problem and the task, the researcher attempted to first identify the students' behaviors at the beginning of the first period. The members talked and discussed the task process. Based on Table 1, before the STEM-based learning through dietary plan lessons, there were 43 students $(55.84 \%)$ who did not communicate and discuss with each other regularly. Meanwhile, there were 24 students $(31.17 \%)$ who thought that they regularly engaged in discussions with group members, and only 10 students $(12.88 \%)$ believed that the members took actions on their own without communicating with others.

In the first group session, the researcher instructed the students in each group to design an experiment to test the presence of nutrients (carbohydrates, proteins, and fats) in food. The groups that communicated and talked about their plan expressed their views as follows:

"We had discussed and agreed on the procedures for the experiment, and then we assigned what food each person needed to bring." S15

"The day we received the assignment, we brainstormed on how to test the nutrients, what food to bring for the experiment, who could bring what." S32

"We gathered to check the worksheet first. Everybody helped reading the procedures, making sure that we understood the task, dividing the tasks into sections, and assigned each person for a section or two persons per section. S73

The members of the groups who admitted having some communication but not frequently reported their group process as follows:

"We discussed in our LINE $^{\mathcal{O}}$ group, but some members did not read the messages." S03

"There was no discussion before the experiment, so we ended up bringing the same materials." S05

"We told each other about what to bring, but we didn't check if we covered every nutrient. So, we missed some experiments." S21

The students in the groups that worked separately without communicating among the group members described their experience as follows:

"No communication." S02

"We separately prepared and tested our own food." S06

"We had a bit of discussion while working in the lab; we asked each other how to proceed for each step." 


\section{$\mathrm{S} 10$}

After the completion of the CPS activities, the students evaluated their group work processes by discussing the problems and how they solved them. In the end, the students completed their second CPS assessment form. The results are shown in Table 1. The findings demonstrated that 48 students $(62.34 \%)$, an increase of 24 students, reported regularly interacting and discussing the task. Meanwhile, 26 students (33.77\%) thought their groups did not regularly communicate or discuss the work procedures. Finally, only three students $(3.9 \%)$ reported not having any communication between the group members and working separately on their own. The students talked about their changing experiences as follows:

"We had discussed beforehand what to do in the experiment. Everyone knew well about the procedure. Then we assigned roles based on their strengths by asking who wanted to do what part." S02

"We discussed before starting the task and divided our roles." S29

"We always discussed and negotiated the types of tasks before enacting the plan." S41

Competency 1.2 Maintaining the Rules of Engagement While Solving the Problem During Rasks Without Getting off Track

Regarding Competency 1.2, the researcher highlighted behaviors when the members collectively worked to solve the problem without getting sidetracked. The results in Table 1 showed that, prior to STEM-based learning through the dietary plan lessons, there were 43 students (55.84\%) who believed their group did not collectively solve problems when they occurred. Whereas 20 students (25.97\%) reported having regular discussions among the group members about problems, 14 students $(18.18 \%)$ reportedly did not discuss the problems with other members and solved them on their own.

The activity for testing the presence of nutrients required prior knowledge in testing the specific nutrients. The problem that occurred test was with carbohydrate testing, as the students forgot to bring food with a drop of Benedict's solution to boil. The color of the copper (II) ion changed from blue to a brick red copper (I) ion. Therefore, the result of the lab experiment did not show the change, even though the food that was being tested contained monosaccharide. Moreover, the result of the experiment was not consistent with what the students had been taught previously. For example, when tested, the result turned green, not blue or brick red. The students were confused and unsure of the experiment. The students who discussed the problem with other members described it as follows:

"If there was a mistake, we worked together to think of how to solve that problem." S19

"We encountered a problem when the experiment went differently from the theory. We discussed and fixed the problem by reassigning the roles to redo the experiment." S51

"When we had a problem, we shared and discussed how to solve it." S72

The groups in which the members did not regularly collaborate explained their working procedures as follows:

"Each person took care of their task first, then helped with other members' problems." S22

"When the problem occurred, there would be one person who was assigned to solve it by telling others to follow." S26

"We worked on the solution only with the ones in charge of the experiment." S68

While working on the lab experiment, the members did not engage in group discussion to find a solution when they encountered a problem. Instead, they chose to ask the teacher. Moreover, they did not attempt to find the solution first before asking the teacher. The following instances showed how the members searched for the solution on their own without discussing it with other members:

"We didn't talk. We solved the problem differently." S2

"We solved our problem independently; we didn't talk." S10

"We didn't collaborate. We handled the problem on our own." S56

The students learned to do the lab experiments several times. Each time, they had a chance to reflect on the problems and factors contributing to group success. It was found that more than half of the students changed their behaviors by collaborating more and discussing the solutions more often rather than focusing on the individual's responsibility. They agreed to work collaboratively as a group. The challenges should be approached together as a group, so everybody needed to help each other. The results of the second assessment of CPS competencies are shown in Table 1. The number of students who reported they had regular interactions and 
discussions when they faced a problem went from 20 to 44 (57.14\%). The number of students who believed they had little interaction and discussion decreased to 28 (36.36\%). Finally, there were only five students (6.49\%) who believed that their group members rarely discussed the problem and sought solutions individually. The students reflected on their group dynamics in the following quotes:

"Everybody worked together to find solutions, for example, when the time is up, we decided together to redistribute the work." S12

"We brainstormed to find the solution; everybody expressed their opinions to solve the problem." S15

"At the beginning when we had different opinions, we went separate ways to do what we were responsible for. Now when we had different ideas, we solved the problems by brainstorming and finding the best way that everybody agreed." S51.

The second competency, Taking appropriate action to solve the problem, can be divided into three subtopics: competency 2.1: Considering the strengths and weaknesses of the member when assigning roles; competency 2.2: Enacting the plan based on the assigned task and role; and competency 2.3: Communicating with team members while performing the task for successful completion.

Of the three subtopics, the behaviors related to the second subtopic were reported occur most often in the group work. Thirty-seven students $(48.05 \%)$ chose to perform the role assigned by the group. After the learning activities, the percentage of students who developed Competency 2.1 (considering the strengths and weaknesses of the member when assigning roles) increased from $33.77 \%$ to $64.94 \%$. Each subtopic is described in detail in the following.

\section{Competency 2.1 Considering the Strengths and Weaknesses of the Members when Assigning Roles}

Most students did not consider the strengths and weaknesses of the group members while working in their groups, and the group leaders were typically selected based on good academic records. Therefore, the roles were simply assigned for superficial reasons; for example, those with neat handwriting would be assigned to write a lab report, while those who like to play around or talk during class would be told to stay still and clean up the equipment after class. The members did not collaborate to establish a plan, so they did not know the opinions and preferences of each person. In the first group session, the individual members did not know what their roles were and only followed the leaders by picking up a few items.

The researcher assigned the lab experiment with food testing, which required careful planning to complete the task on time. In fact, after the first experiment, two-thirds of the students failed because they ran out of time. This was because only one or two members of the group were engaged in the task. The rest of the group members did not know what to do. Some students might have been competent, but they were not confident enough to volunteer to contribute to the experiment because they viewed themselves as mediocre. The results from the first CPS assessment indicated that there were only 26 students $(33.77 \%)$ in the groups that always considered the strengths and weaknesses of the other members. Whereas 41 students $(53.25 \%)$ said they sometimes considered their peers' abilities in the role assignment, nine students (12.99\%) admitted that they did not consider this at all. The following quotes illustrate examples of the behaviors the students believed occurred with regard to assigning roles based on their peers' abilities.

"We let the person who understood the task assign the roles; other people will complete the task based on their assigned role." S20

"We divided the task well so we know who would be responsible for which part." S35

"Before the task, each member had been informed of their roles as well as the overall picture of today's task." S15

The students who sometimes, but not regularly, considered the members' strengths and weaknesses expressed their opinions as follows:

"We divided the roles, but it might not match their potentials." S1

"When we experimented, we assigned the role for each person without actually knowing that that person could do it best." S8

"Mostly, we assigned the roles based on their responsibilities more than their potentials; for instance, in the food testing, the first step was to grind the food. Even though we already assigned this role, but in the lab preparation, we ground the food we brought in." S33.

The students who didn't consider the members' abilities reported their group dynamics as follows: 
"We didn’t assign roles clearly." S11

"There was no division of tasks." S21

"Some members only followed what they were told without showing their potentials." S44

The results of the second CPS assessment following the CPS activities are presented in Table 1. The students asked their group members about their strengths before assigning a role. After several collaborative activities, each person's strengths and weaknesses were revealed. Fifty students (64.94\%), an increase from the previous 26, believed that their groups considered the strengths and weaknesses of the team members and assigned appropriate roles to them. Twenty-three students $(28.87 \%)$ believed that they sometimes considered the strengths and weaknesses and assigned appropriate roles. Only four students (5.19\%) still did not think that their group members' potential and appropriate role assignments were considered. The students reported their changed work process as follows:

"After working together several times, we started to know the potentials of each member, so we assigned the roles based on their potentials." S8

"There was an appropriate role assignment for each person, and everyone shared equal responsibility." S11

"There was a role assignment based on their abilities. Some were good at planning, some were good at searching for information, some were good at summarizing the lab results. Each person worked on what they did best." S44

\section{Competency 2.2 Enacting the Plan Based on the Assigned Task and Role}

Competency 2.2 involves enacting the plan based on the assigned task and role. This competency was reported to be found most frequently in the group work. The students believed that in group work sessions, each person needed to be assigned a role and to perform the task according to that role. The data from the interviews provided additional information showing that the role assignment was done by a single person without considering the strengths and weaknesses of the members or discussing the plan. The first CPS competency observation revealed that 37 students $(48.05 \%)$ enacted the plan based on the assigned task. Thirty-four students $(44.16 \%)$ reported that their groups performed their assigned tasks, although not regularly, as they sometimes spent time socializing or not following the plan. Six members (7.79\%) thought their groups did not perform their assigned task. The following quotes refer to the students who performed their tasks.

"Everyone performed their tasks based on their assigned roles and they performed attentively." S9

"Once assigned, everyone performed their task attentively." S22

Several students thought that, when engaging in group works, the members followed their roles, although not regularly. They spent time socializing and did not follow through with their plan. They expressed their opinions as follows:

"Everyone worked on their assigned role, but sometimes they were meddling with others." S21

"Most people were well responsible for their duties, though sometimes they wandered off the task" S27

The students who did not think their groups followed the assigned roles and did not perform according to the plan expressed their opinions as follows:

"Some members were not responsible, did not perform their task, and did not tell the others. Therefore, we couldn't conduct the experiments because there was no food to use in the experiments." S54

"Some members did not remember their duties. They didn't tell anyone when they were absent from school." S50

After completing the CPS observation form, the students worked in groups several times, which involved the lab experiments on the nutrients and information search activities using a jigsaw technique. After the activities, they completed an evaluation to revise and develop their collaborative skills with others. Subsequently, they completed the second CPS observation form. The results indicated that 37 students $(77.62 \%)$ out of 60 made progress by enacting the plan based on their assigned roles. The number of students who still spent time socializing and interfering with other people's tasks declined from 34 to $15(19.48 \%)$. Finally, the number of students who abandoned their tasks decreased to two $(2.60 \%)$. The following quotes reflect their changed collaborative behaviors:

"After discussion and a clear role assignment, everyone performed their tasks well and finished it in time." S41 
"We were assigned the roles that we were capable to do, so we did well on our tasks. We even had enough time left to help when our friends asked for help." S55

"After discussing, we all understood the importance of roles and responsibilities. So we got a good result and were willing to help each other." S11

\section{Competency 2.3 Communicating with Team Members while Performing the Task for Successful Completion}

In collaborating with others, the students felt that they were regularly communicating while participating in the activities. However, their communications can be divided into different purposes; for example, a discussion to solve a problem, an exchange to inform other members about what they had done, or a discussion to explain to other members which data from the interviews identified this type of communication as the group leaders giving orders. Based on first CPS observation, there were 24, 31, and 22 students exhibiting this behavior regularly, often but not consistently, and seldom, respectively. The students who regularly communicated with the groups expressed their opinions as follows:

"During the lab experiment, we communicated all the time to report the progress." S8

"We always discussed during the experiment because we were afraid of making a mistake." S38

The students who felt that their group members often but not always communicated voiced their opinions as follows:

"We talked about progress, but not so much." S37

"We discussed before assigning roles and tasks, but everyone was busy with their task until we forgot to follow up with others. When we completed our work, we reported our results." S22

The students who did not communicate during the activities expressed the following views:

"We clearly divided our roles. Everyone was responsible for his/her work. We checked on our progress a little bit." S26

"We separately did our job without communicating during the task." S49

In later activities, the teacher asked each group to present problems and how to solve them through discussion with the whole class. During the group work, the students expressed their opinions about communication. Some students believed that only talking and asking questions would be enough for group communication. Additional questions were asked by the teacher about the problems within their groups; for instance, which group brought up the problems they experienced and helped each other find the solution. When some groups provided an example of the problem they encountered and talked about how they discussed possible solutions and solved it, other students learned and better understood how to communicate to solve the group problems. Thereafter, the students started to discuss more before, during, and after the task. When they completed the task, they discussed the results of the experiment together. In contrast to the first activity, the member who wrote the report was solely responsible for the discussion and conclusion. Consequently, when they completed the second CPS observation, the results revealed that 33 students displayed this behavior regularly. Thirty-five students expressed this behavior often but not regularly, and only nine students rarely did. The following excerpts reflect their opinions on the changed behaviors:

"We always discussed during our work. We interacted more often and brainstormed to find out why our experiment went wrong." S51

"We asked each other about the progress of the work. When we encountered a problem, everyone was willing to set aside their job and helped solve the problems together." S32

"We discussed every time we finished each step. We communicated about the steps and sequence of the tasks all the time." S73

The third competency, Establishing and maintaining team organization. This competency consists of two components: competency 3.1: Adapting the team organization or roles when facing an unexpected situation; and competency 3.2: Monitoring and providing feedback about the group success. The students focused on reassigning roles rather than on providing feedback and reflecting with group members. Thirty-two students $(41.56 \%)$ confirmed that, when they encountered a problem, they always fixed it by reassigning the roles. Regarding feedback, only 23 students (29.87\%) said that they provided feedback and reflected on their work with the group members. After the group work activities, it was found that $70.13 \%$ of the students developed Competency 3.1, while $45.45 \%$ developed Competency 3.2 (a detailed description is presented below). 


\section{Competency 3.1 Adapting the Team Organization or Roles when Facing an Unexpected Situation}

During the group work, the students assigned their roles from the beginning. There was a member who was in charge of the experiment, another who took notes and wrote the report, and others who cleaned up the lab equipment. When they encountered a problem, such as a failed experiment, the students who did the experiment needed to figure out a solution by themselves by asking other groups or the teacher. Most of them did not discuss possible solutions with their group members. Sometimes, they knew that some members had abilities that better suited the job, but they did not reassign the role appropriately. However, despite the lack of collaborative solutions, everyone was ready to switch their roles depending on the group leaders' suggestions. Therefore, when completing the first CPS observation, most students (44.16\%) believed that they switched their roles sometimes but not always when they faced a problem. A total of $41.56 \%$ of the students were able to always change their roles when they encountered a problem. Only $14.29 \%$ of the students did not shift their roles at all. The following excerpts reflect the students' behaviors.

"When we had a problem and couldn't continue, we helped each other or switched our roles." S12

"Everyone was willing to change their roles to make the job successful." S29

"Everyone was ready to listen to and helped each other solving problems. We might take other roles to make the experiment successful." S1

Most students thought that they could shift their roles, but not every time. They expressed their views as follows:

"Sometimes we couldn't find anyone who wanted to take the role, so we needed to switch our roles from time to time." S21

"We helped each other at any stage when we came across a problem, but there were some members who did not want to change their responsibility." S62

"To solve the problem, we could call for help." S27

The students who said they did not switch roles even if they had a problem expressed the following views:

"We could not make any changes. We realized that we were wrong after learning from other groups." S32

"When we had a problem, we only gave suggestions, but they had to solve their own problems." S48

"If we knew how to make the lab experiment better, we would immediately do it without discussing it with others in the group." S26

When completing the second CPS assessment after the activities, the students saw some examples of collaboration and problem-solving methods, so they reassigned roles and responsibilities to match the members' abilities and working process. Most students changed their plans. When they encountered a problem, they turned to each other to find a solution. When it was necessary to adjust their roles, they were ready to follow the group agreement. Accordingly, the proportion of students who modified their plans or roles increased from $41.56 \%$ to $70.13 \%$. Nineteen students $(24.68 \%)$ said their groups frequently revised their roles once a problem occurred, while only four students $(5.16 \%$, decreasing from 11 in the first assessment) claimed that there was no change in their groups. The students mentioned their revised plans:

"We reassigned the role to a more appropriate member to replace the one who couldn't complete the task. "S51

"When we faced a challenge, we discussed it, which made us understand each other more, and agreed to change for the better." S25

"When we had a problem, we could switch roles or help each other to work together more smoothly." S41

\section{Competency 3.2 Monitoring and Providing Feedback about the Group's Success}

The students rarely monitored and provided feedback on role assignment and group work processes. The majority of the students preferred to compromise. When they were assigned any roles, they would do their best. Only a few students complained about their duties because they were not familiar with the tasks. Based on the interviews, if any members refused to perform any assigned tasks, they would be seen as selfish and demanding. Therefore, the roles and responsibilities were assigned by the group leaders only. In the event the leaders let the members choose their roles, the members who were quick to speak up had the right to choose first. When they faced difficulties, none determined whether the cause was due to a particular person or task. Everyone particularly avoided talking about the problem if it was due to someone's mistake. Therefore, according to the results from the first CPS observation, $44.16 \%$ of the students felt that only a few members of the group engaged 
in providing feedback. While $29.87 \%$ of the students believed that all group members participated in the feedback and reflection, $25.97 \%$ did not think that there was any feedback or reflection on the role assignments and group work processes. They expressed their opinions in the following excerpts:

"The members discussed work and evaluated our performance." S5

"We honestly expressed our opinions, listening to each other to find out a better solution." S73

"Everyone shared their opinions on the planning and steps for completing the task." S11

The following excerpts reflected the opinions of the students about certain members providing feedback:

"Only a few members shared their thoughts. Some disagreed but said nothing." S14

"Some members were afraid to voice their ideas about the role assignment." S29

"We tried to share our ideas and make suggestions on the planning, but some members may be afraid of expressing their opinion." S55

The students who felt that their group members did not participate in the reflection process shared their thoughts:

"We did not talk about the roles and responsibilities at all. Nobody expressed their opinions." S21

"The members just followed the order; they neither spoke up nor suggested anything." S23

"We did not communicate among members in the group. When they were assigned a role, they said fine and no more suggestions." S7

After the group work evaluation, the researcher asked questions about what had led to the problems and attempted to encourage the students to share their ideas on the mismatched roles and responsibilities. In the early rounds of evaluation, they were afraid to talk openly about the problems. However, after several rounds of activities, the students started to become familiar with finding the cause of the problems. As a result, they had more discussions regarding the inappropriate role assignments of the group members. However, they were careful not to hurt each others' feelings. At the end of the activities, the findings from the second CPS observation indicated that $45.45 \%$ of the students thought that their group members regularly provided feedback to each other, whereas the same number of students said only a few members engaged in providing feedback. Only $9.09 \%$ of the students still did not think that there was any monitoring or feedback provided. Here are some excerpts demonstrating the changes in their ideas:

"When we had a discussion, we developed collaborative skills. Therefore, the members understood and performed their tasks properly." S3

"Everyone shared their thoughts about the appropriateness of the role assignment, then provided opinions on work planning and how to run the work smoothly." S11

"After working together for a while, we were more comfortable to share and participate in giving opinions and planning our work." S29

\section{Conclusion, Discussion, and Recommendations}

After the implementation of STEM-based learning using dietary plan lessons to enhance the students' CPS competencies, the researcher discovered that the learners developed all three competencies. First, they learned to establish and maintain shared understandings. Previously, the students were accustomed to having a group leader giving orders while others followed and working separately without collaborating within the groups. Through the implementation, they developed their communication skills and began to engage in discussions about the work procedures. Additionally, when they faced a challenge, they felt that it was a shared responsibility rather than one person's duty. Thus, they would try to solve it collaboratively. This action is consistent with Graesser et al. (2018), who claimed that collaborative group work requires a shared goal. Each member should not try to solve the problem alone. Regarding the second competency, taking appropriate action to solve the problem, the students were accustomed to their roles being assigned by the group leader without consideration of their strengths and weaknesses. Hence, they failed to achieve their goals successfully. After the lessons, they started to consider their task collaboratively and followed the planned procedures. This finding is also in line with Graesser et al. (2017), who argued that group members need to explain the steps to be taken to find the solution and to act according to the plan. In solving the problem, the members need to communicate, explain, and negotiate to arrive at a conclusion. Third, in terms of establishing and maintaining team organization, the learners were not initially aware of the role of feedback. However, after the activities, the learners started to give feedback to each other. Consequently, they developed shared understandings and completed their tasks as planned. According to Kozlowski and Ilgen (2006), the members of the group need to perform their roles within the group, collectively 
manage any difficulties, communicate the important messages, and provide feedback and reflection to the other group members.

In conclusion, this research focused on the development of CPS competencies to prepare learners to work collaboratively with others and to develop their problem-solving skills. These skills are considered essential in the 21 st century. The crucial recommendation in organizing group work activities is to allow learners to discuss and provide feedback on their tasks. Teachers should take the role of active facilitator to mediate the relationships among students in the groups (Rozenszayn \& Ben-Zvi Assaraf, 2011).

The main challenge of implementing STEM-based learning through dietary plan lessons to promote CPS competencies is time limitations. It is important to allow time for the students to talk about the problems, for whole-class discussions about the solution, and for discussing the factors that contribute to obtaining successful results. All of these activities are important for collaboration and social skills development. Therefore, the lesson must be conducted efficiently to allow sufficient time for feedback. In addition, the assigned task should be challenging to allow the learners to practice solving a problem collaboratively, thus enhancing their group work skills. Moreover, learners need to spend time understanding and learning about their group members. Thus, they should continue to work with the same group members to develop their group work competencies. The findings indicated that the students' group work skills developed, but only within a familiar setting. These results could have been different if the students had been in a new environment. Thus, the instructional activities should be conducted continuously with students rotated into new groups to practice their teamwork skills with others.

Scientific inquiries are an important factor contributing to the development of CPS competencies. The members of the groups can exchange information, discuss, and engage in debate to find a solution to the problem. Hence, aside from the STEM-based instruction, the project-based approach is also appropriate for developing CPS competencies.

\section{References}

Barron, B. (2000). Achieving coordination in collaborative problem-solving groups. The Journal of the Learning Sciences, 9(4), 403-436. https://doi.org/10.1207/S15327809JLS0904_2

Binkley, M., Erstad, O., Herman, J., Raizen, S., Ripley, M., Miller-Ricci, M., \& Rumble, M. (2012). Defining twenty-first century skills. In Assessment and teaching of 21st century skills (pp. 17-66). Dordrecht: Springer. https://doi.org/10.1007/978-94-007-2324-5_2

Bungum, B., Bøe, M. V., \& Henriksen, E. K. (2018). Quantum talk: How small - group discussions may enhance students' understanding in quantum physics. Science Education, 102, 856-877. https://doi.org/10.1002/sce. 21447

Bybee, R. W. (2013). The case for STEM education: Challenges and opportunities. Arlington, VA: NSTA Press.

Chamrat, S. (2017). The definition of STEM and key features of STEM education learning activity. STOU Education Journal, 10(2), 13-34.

Cohen, L., Manion, L., \& Morrison, K. (2007). Research methods in education (6th ed.). New York, NY: Routledge. https://doi.org/10.4324/9780203029053

Edmunds, J., Arshavsky, N., Glennie, E., Charles, K., \& Rice, O. (2017). The relationship between project-based learning and rigor in STEM-focused high schools. Interdisciplinary Journal of Problem-Based Learning, 11(1), 3. https://doi.org/10.7771/1541-5015.1618

Graesser, A., Kuo, B. C., \& Liao, C. H. (2017). Complex problem solving in assessments of collaborative problem solving. Journal of Intelligence, 5(2), 10. https://doi.org/10.3390/jintelligence5020010

Graesser, A. C., Fiore, S. M., Greiff, S., Andrews-Todd, J., Foltz, P. W., \& Hesse, F. W. (2018). Advancing the science of collaborative problem solving. Psychological Science in the Public Interest, 19(2), 59-92. https://doi.org/10.1177/1529100618808244

Griffin, P., \& Care, E. (Eds.). (2014). Assessment and teaching of 21st century skills: Methods and approaches. Springer. https://doi.org/10.1007/978-94-017-9395-7

Hennessy, S., \& Murphy, P. (1999). The potential for collaborative problem solving in design and technology. International Journal of Technology and Design Education, 9(1), 1-36. https://doi.org/10.1023/A:1008855526312

Hesse, F., Care, E., Buder, J., Sassenberg, K., \& Griffin, P. (2015). A framework for teachable collaborative problem-solving skills. In Assessment and teaching of 21st century skills (pp. 37-56). Dordrecht: Springer. 
https://doi.org/10.1007/978-94-017-9395-7_2

Innes, R. B. (2007). Dialogic communication in collaborative problem-solving groups. International Journal for the Scholarship of Teaching and Learning, 1(1), n1. https://doi.org/10.20429/ijsotl.2007.010104

Kemmis, S., \& McTaggart, R. (1988). The action research planner (3rd ed.). Victoria: Deakin University.

Kim, M., \& Tan, H. T. (2013) A collaborative problem-solving process through environmental field studies. International Journal of Science Education, 35(3), 357-387. https://doi.org/10.1080/09500693.2012.752116

Kozlowski, S. W., \& Ilgen, D. R. (2006). Enhancing the effectiveness of work groups and teams. Psychological Science in the Public Interest, 7(3), 77-124. https://doi.org/10.1111/j.1529-1006.2006.00030.x

Lamminpää, J., \& Vesterinen, V. M. (2018). The use of humour during a collaborative inquiry. International Journal of Science Education, 40(14), 1718-1735. https://doi.org/10.1080/09500693.2018.1508926

Lertdechapat, K., \& Promratana, P. L. (2018). Effects of collaborative inquiry on collaborative problem-solving ability of lower secondary school students. Journal of Education Studies, 46(2), 1-20.

Nelson, L. M. (1999). Collaborative problem solving. In C. M. Reigeluth (Ed.), Instructional-design theories and models (Vol. II: A new paradigm of instructional theory, pp. 241-267). Mahwah, NJ: Lawrence Erlbaum Assaciates.

Organisation for Economic Co-operation and Development. (2017). PISA 2015 Results (Volume V: Collaborative problem solving). PISA, OECD Publishing, Paris. https://doi.org/10.1787/9789264285521-en

Radloff, J., \& Guzey, S. (2016). Investigating preservice STEM teacher conceptions of STEM education. Journal of Science Education and Technology, 25(5), 759-774. https://doi.org/10.1007/s10956-016-9633-5

Rozenszayn, R., \& Ben-Zvi Assaraf, O. (2011). When collaborative learning meets nature: Collaborative learning as a meaningful learning tool in the ecology inquiry-based project. Research in Science Education, 41, 123-146. https://doi.org/10.1007/s11165-009-9149-6

Sampson, V., \& Clark, D. (2009), The impact of collaboration on the outcomes of scientific argumentation. Science Education, 93, 448-484. https://doi.org/10.1002/sce.20306

Sohr, E. R., Gupta, A., \& Elby, A. (2018). Taking an escape hatch: Managing tension in group discourse. Science Education, 102, 883-916. https://doi.org/10.1002/sce.21448

Tao, P. (1999). Peer collaboration in solving qualitative physics problems: The role of collaborative talk. Research in Science Education, 29, 365-383. https://doi.org/10.1007/BF02461599

\section{Copyrights}

Copyright for this article is retained by the author, with first publication rights granted to the journal.

This is an open-access article distributed under the terms and conditions of the Creative Commons Attribution license (http://creativecommons.org/licenses/by/4.0/). 